\title{
BMJ Open Global dietary quality, undernutrition and non-communicable disease: a longitudinal modelling study
}

\author{
Rosemary Green, ${ }^{1,2}$ Jennifer Sutherland, ${ }^{1,2}$ Alan D Dangour, ${ }^{1,2}$ \\ Bhavani Shankar, ${ }^{2,3}$ Patrick Webb ${ }^{4}$
}

To cite: Green R,

Sutherland J, Dangour AD, et al. Global dietary quality, undernutrition and noncommunicable disease: a longitudinal modelling study. BMJ Open 2016;5: e009331. doi:10.1136/ bmjopen-2015-009331

- Prepublication history and additional material is available. To view please visit the journal (http://dx.doi.org/ 10.1136/bmjopen-2015009331).

Received 7 July 2015 Revised 11 November 2015 Accepted 13 November 2015

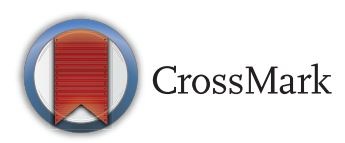

For numbered affiliations see end of article.

Correspondence to Dr Rosemary Green; rosemary.green@Ishtm.ac.uk

\section{ABSTRACT}

Objectives: To determine the relationship between global dietary energy availability and dietary quality, and nutrition-related health outcomes.

Design: A worldwide longitudinal modelling study using country-level data. Data on total dietary energy availability and dietary energy from 10 distinct food groups (as a proxy for dietary quality) were obtained from the FAO Food Balance Sheets database.

Indicators of development were abstracted from the World Bank's World Development Indicators database. Data on nutrition and health outcomes were taken from the WHO mortality database and major crosscountry analyses. We investigated associations of energy availability from food groups and health and nutrition outcomes in the combined data set using mixed effects models, while adjusting for measures of development.

Population: 124 countries over the period 19802009.

Main outcome measures: Prevalence of stunting in children under 5 years and mortality rate from ischaemic heart disease (IHD) in adults aged 55+ years.

Results: From 1980 to 2009, global dietary energy availability increased, and rates of child stunting and adult IHD mortality declined. After adjustment for measures of development, increased total dietary energy availability was significantly associated with reduced stunting rates $(-0.84 \%$ per $100 \mathrm{kcal}$ increase in energy, $95 \% \mathrm{Cl}-0.97$ to -0.72 ) and nonsignificantly associated with increased IHD mortality rates (by 4.2 deaths per $100000 / 100 \mathrm{kcal}$ increase, $95 \% \mathrm{Cl}-1.85$ to 10.2$)$. Further analysis demonstrated that the changing availability of energy from food groups (particularly fruit, vegetables, starchy roots, meat, dairy and sugar) was important in explaining the associations with health outcomes.

Conclusions: Our study has demonstrated that by combining large, publicly available data sets, important patterns underlying trends in diet-related health can be uncovered. These associations remain even after accounting for measures of development over a 30year period. Further work and joined-up multisectoral thinking will be required to translate these patterns into policies that can improve nutrition and health outcomes globally.

\section{Strengths and limitations of this study}

- This is the first global study to explore the impact of total energy availability as well as dietary quality on major nutrition and health outcomes.

- Through data linkage, the study was also able to adjust for the effect of key measures of development.

- This is a country-level rather than individual-level observational study, and therefore cannot investigate causal relationships.

- Some data may be subject to measurement error, but this will be likely to have resulted in underestimation rather than overestimation of effect sizes.

\section{BACKGROUND}

Agricultural production has largely kept pace with demands for food, from a growing global population, ${ }^{1}$ in terms of per capita dietary energy (kilocalorie) availability, and cross-country evidence suggests that this increased energy availability has had a generally positive impact on nutrition outcomes such as child stunting. ${ }^{2}$ However, the number of stunted children under the age of 5 years was estimated to be 159 million in 2015 indicating that it remains a major global burden. ${ }^{3}$ At the same time, the number of children and adults who are overweight or obese has been rising, including in many low income countries of Asia and Africa that are simultaneously tackling the unresolved burden of undernutrition. ${ }^{4}$

A focus of the agriculture sector has been to ensure increased production of staple foods such as cereals, and country-level analyses have shown that dietary energy availability largely from cereals is positively associated with growth in childhood but concerningly it is also associated with overweight in adults. $^{2}{ }^{5-7}$ Furthermore, the wider nutritional requirements of healthy diets have 
received less attention from the agriculture sector, ${ }^{8}$ and recent analyses have shown that global diets are becoming increasingly polarised between healthy and unhealthy patterns. ${ }^{9}$ Previous reports of the relationship between dietary quality and nutrition and health outcomes have typically been limited to individual countries or specific foods. For example, in Poland, changes since the 1990s in the availability of different dietary fats and increased availability of fresh fruit and vegetables have been associated with reductions in cardiovascular mortality. ${ }^{10}$ In cross-sectional ecological studies, the availability of dietary energy from sugar and animal fats is associated with the prevalence of obesity, cardiovascular disease (CVD) and diabetes. ${ }^{11-13} \mathrm{~A}$ small number of multicountry longitudinal analyses have identified several diet-health associations including between palm oil availability and ischaemic heart disease (IHD) mortality and between sugar availability and diabetes prevalence. $^{1415}$

This paper takes a global perspective on the associations of food availability and dietary quality with nutrition and health outcomes. The specific aim is to explore the associations of national-level dietary energy availability and dietary quality with nutrition and health outcomes in 124 countries from 1980 to 2009 while adjusting for key measures of national development. The analyses address for the first time at this scale the association of dietary quality (measured as the proportion of total dietary energy available from individual food groups) with measures of both undernutrition and diet-related non-communicable disease (NCD). In our analysis, stunting in childhood was selected as the measure of undernutrition as it is a reflection of, among other things, chronic exposure to a poor quality diet in early life. ${ }^{16}$ IHD was selected as the measure of diet-related NCD, as it is the leading global cause of death and is also associated with chronic consumption of a poor quality diet. ${ }^{17}$

\section{METHODS}

\section{Data sources}

The initial database used was a complete download of the FAOSTAT database for all countries and all years available (http://faostat3.fao.org/home/E). This included 181 separate countries. We restricted this data set to the years 1980-2009, and to the food commodities necessary for the study (total energy available per capita per day, and energy available from 10 major food groups -animal fats, cereals, fruit, meat, milk products, pulses, starchy roots, sugar and sweeteners, vegetables and vegetable oils). We subtracted the calories from alcohol from the total energy availability variable. Nine countries were excluded due to changing borders over time, resulting in a database of 172 countries. For these countries, we classified eight regions based on the World Bank classification: East Asia and Pacific, Eastern Europe and Central Asia, Latin America and the Caribbean, Middle
East and North Africa, South Asia, sub-Saharan Africa, US and Canada, and Western Europe.

Data on measures of development taken from the World Development Indicators, Agricultural Distortions Database and health outcomes were matched into this database for the available countries and years. The variables added were: gross national income (GNI) in current US\$, percentage of population employed in agriculture, percentage of population living in urban areas and the relative rate of assistance for agriculture (RRA). Following matching, 22 countries were excluded from the database due to missing data (countries where no data at all for any year were available for at least one of the selected variables). We included the RRA only in subgroup analysis, as this variable was only available for a subset of countries. Data from the Lancet series on child stunting from 1985 to 2009 were also merged with the database, ${ }^{18}$ along with data on mortality from IHD among people aged 55+ from the WHO Mortality Database 1980-2009 (http://apps.who.int/healthinfo/ statistics/mortality/whodpms/). We also obtained information on the population of each country in each year from a combination of the WHO Mortality Database and data held by FAOSTAT. The final database contains 124 countries, 78 of which included data on the prevalence of stunting, and 79 of which included data on mortality from IHD (see figure 1). Data on the variables included and their sources can be found in table 1 .

\section{Missing data}

There were no missing years of data in our data set for food availability or for child stunting rates. The child stunting data set included some imputed data. ${ }^{18}$ Most other variables included in the analysis had some missing years of data, ranging from $1 \%$ missing in the percentage of population living in urban areas to $48 \%$ missing in the percentage of the population employed in agriculture. Where necessary, data were imputed by country to remove missing years of data for each variable separately. Where there were only a small number of missing years of data for a country, data were imputed based on time trends for the years where data were available for that country. Where more years of data were missing, time-trends in similar countries were also used in the models in order to increase robustness of the estimates.

\section{Statistical analysis}

We explored time trends in availability of all food groups, and constructed line graphs to show trends in the prevalence of the health outcome variables (child stunting and mortality from IHD), both overall and within each region. Next, we constructed mixed effects linear regression models to explore relationships between food availability, measures of development and health outcomes. To assess the relevance of the heterogeneity in food availability in different world regions, we 
Figure 1 Steps in construction of a global database combining data from FAOSTAT, World

Development Indicators and health and nutrition data from published analyses.

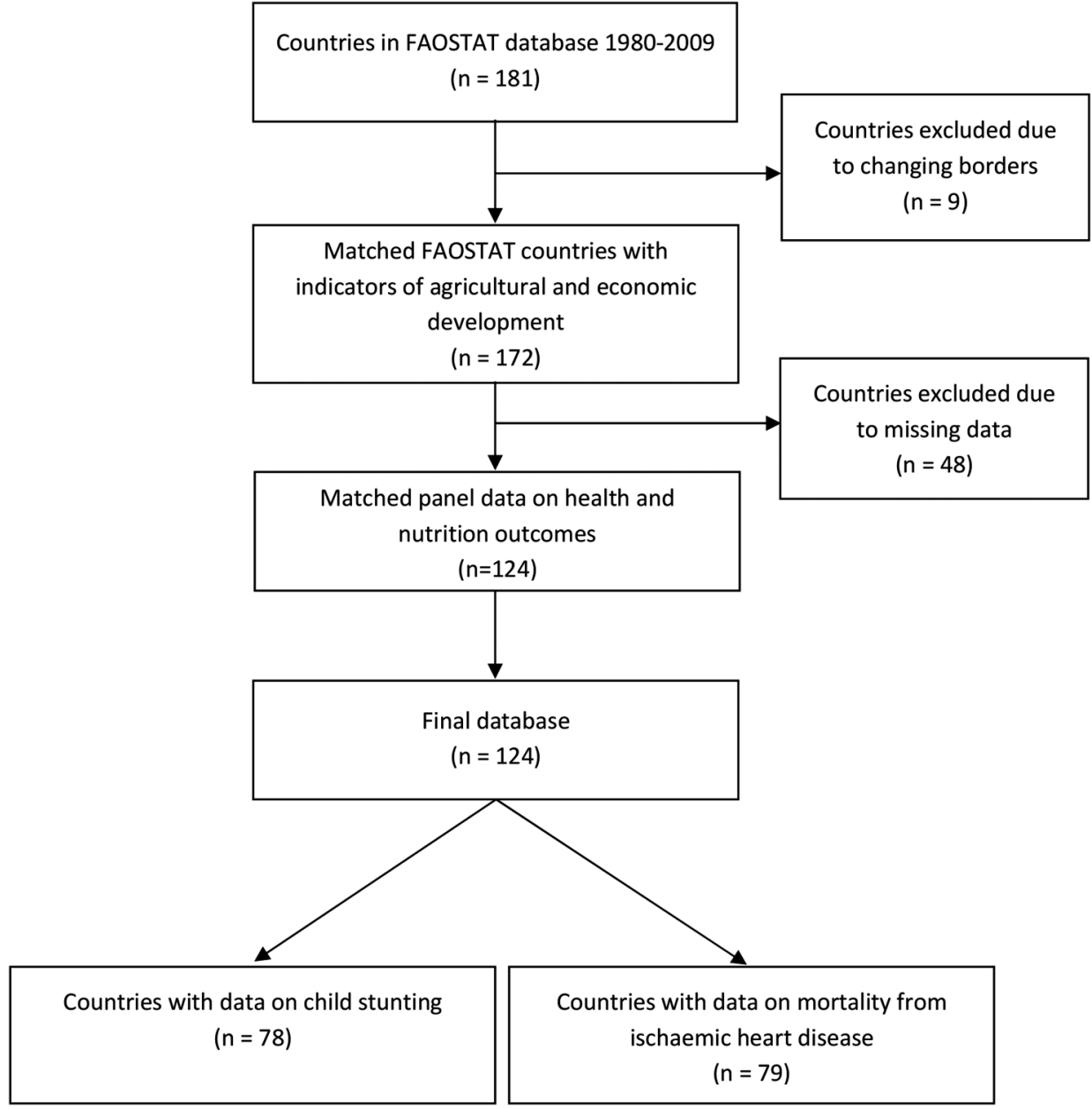

included World Bank Region as an area-level effect in these models.

We constructed separate models for the two health outcomes examined, and initially added total energy availability per capita per day as a predictor. We then added measures of economic and agricultural development (GNI, employment in agriculture and urban population) as covariates, and analysed the impact of energy availability separately by World Bank Region in order to assess variability in the data. We also constructed a second set of models in which energy availability from each food group as a proportion of

Table 1 List of variables used in analyses

\begin{tabular}{|c|c|c|c|}
\hline Variables & Description & Data source & $\begin{array}{l}\text { Years } \\
\text { available }\end{array}$ \\
\hline \multicolumn{4}{|l|}{ Food availability } \\
\hline $\begin{array}{l}\text { Total energy availability } \\
\text { Energy available from major food groups }\end{array}$ & $\begin{array}{l}\text { Mean energy available per capita } \\
\text { (kcal/day) }\end{array}$ & FAOSTAT $^{19}$ & 1980-2009 \\
\hline \multicolumn{4}{|l|}{ Health outcomes } \\
\hline Child stunting $<5$ years & $\begin{array}{l}\% \text { of children with height-for-age } \\
\text { z-score }<-2\end{array}$ & Stevens et $a l^{18}$ & 1985-2009 \\
\hline Ishaemic heart disease & Mortality rate among individuals aged $\geq 55$ & $\begin{array}{l}\text { WHO mortality } \\
\text { database }^{20}\end{array}$ & 1980-2009 \\
\hline \multicolumn{4}{|l|}{ Development indicators } \\
\hline Gross national income (GNI) & GNI per capita (2014 \$US) & World Development & 1960-2013 \\
\hline Employment in agriculture & $\%$ of total employment & Indicators ${ }^{20}$ & \\
\hline Urbanisation & $\%$ population living in urban areas & & \\
\hline $\begin{array}{l}\text { Relative rate of assistance for agriculture } \\
\text { (RRA) }\end{array}$ & $\begin{array}{l}\text { Relative policy support to agriculture vs } \\
\text { non-agriculture }\end{array}$ & $\begin{array}{l}\text { Agricultural distortions } \\
\text { database }^{21}\end{array}$ & 1955-2010 \\
\hline
\end{tabular}


total energy was added as a separate predictor. Again, these models were run before and after adjustment for measures of economic and agricultural development. For the models exploring changes in mortality from IHD, we employed a 10-year time lag between the measures of food availability and development and the outcome measure, in order to allow for the likely delayed impact of nutritional status on IHD mortality. The introduction of this time-lag reduced the final sample size of country-years for analysis on IHD mortality.

Descriptive analyses and imputations were performed in SPSS V.20 for Windows (IBM) and mixed effects modelling was performed in Stata V.13.2 for Windows (StataCorp).

\section{RESULTS}

\section{Total dietary energy availability and nutrition and health} outcomes

From 1980 to 2009, per capita dietary energy availability increased worldwide (figure 2) with the steepest increase seen (from an already high level) in the US and Canada and a dramatic fall seen in Eastern Europe and Central Asia at the time of the breakup of the Soviet Union. ${ }^{22}$ Over the same period, global stunting rates declined steadily and IHD mortality rates declined relatively slowly (see web materials figures S1 and S2). These global findings mask large differences between regions: stunting declined much less in sub-Saharan Africa than in other regions, and some regions (including sub-Saharan Africa and South Asia) showed large increases in IHD mortality rates. In other parts of the world, such as North America, there were marked declines in IHD mortality rates.

Associations between dietary energy availability and nutrition and health outcomes were explored in a random effects model that included 1950 observations for stunting, and 1580 observations for IHD mortality. Across all regions and years, after adjusting for various measures of development (including income, urban population and employment in agriculture), an increase of $100 \mathrm{kcal}$ per person per day in dietary energy availability was associated with a statistically significant $0.84 \%$ reduction $(95 \%$ CI $-0.97 \%$ to $-0.72 \%)$ in child stunting from 1985 to 2009 (see table 2). The same increase in energy was associated with a non-significant increase in IHD mortality rates of 4.2 deaths $(95 \%$ CI -1.85 to 10.2$)$ per 100000 population from 1990 to 2009 .

When analysed separately by World Bank Region, the overall pattern of relationships remained consistent in most cases (table 3). The significant inverse association between energy availability and stunting rates remained although this tended to be stronger in Asian countries and weaker in sub-Saharan Africa and Latin America. Stunting prevalence in Western Europe and the US and Canada was too low to allow us to analyse these regions separately. For IHD mortality, the positive association between energy availability and mortality rate remained when analysed separately by World Bank Region, but the association was stronger in more developed regions and negligible in less developed regions.

\section{Dietary quality and nutrition and health outcomes}

Global dietary energy availability from cereals remained relatively constant over the period 1980-2009 at around $1100 \mathrm{kcal} /$ capita/day, representing approximately $40 \%$ of total energy available (table 4). From 1980 to 2009, mean availability of energy from vegetable oils increased by $39 \%$, and availability of energy from fruits and vegetables also increased by $10 \%$ and $42 \%$ respectively (figure 3 ). There were declines in availability of energy from sugar by $7 \%$ and from animal fats by $28 \%$. Sugar, oils, meat, dairy and starchy roots provided the largest share of energy availability from non-staple sources (table 4), with absolute dietary energy availability from fruits and vegetables remaining low despite the increases identified over the period under study.

Increased availability of energy from six of the nine non-cereal food groups was associated with significantly lower stunting rates (table 5). In particular $100 \mathrm{kcal}$ proportionately greater energy availability from vegetables, milk products and sugar was associated with $3.5 \%, 2.1 \%$ and $1.8 \%$ lower stunting rate respectively. Increased
Figure 2 Mean energy availability from all food sources (excluding alcohol) 1980-2009, by World Bank Region.

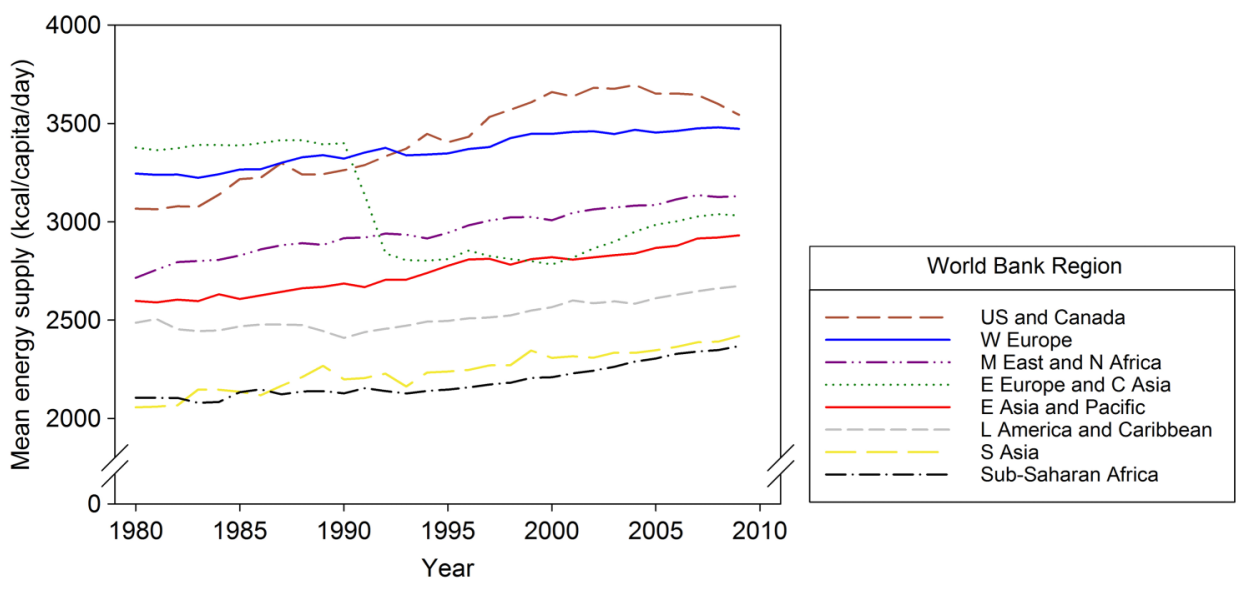


Table 2 Mixed effects regression model showing relationships between global total energy availability and health outcomest

\section{Impact of total energy availability per capita per day (100 kcal} increase) on health outcome

\section{Change in health outcome ( $95 \% \mathrm{Cls})$}

Adjusted for year of measurement

Adjusted for all covariates¥

Percentage of children stunted $(n=1950)$

IHD mortality rate per 100000 in adults aged $55+\S(n=1580)$
$-0.84(-0.97 \text { to }-0.72)^{\star \star \star}$

$4.20(-1.85$ to 10.2$)$

${ }^{*} p$ value for coefficient $<0.05 ;{ }^{* *} p$ value for coefficient $<0.01 ;{ }^{* \star *} p$ value for coefficient $<0.001$.

†Model includes World Bank Region as an area-level effect.

$\ddagger$ Adjusted for year of measurement, gross national income, percentage employment in agriculture and percentage living in urban areas.

§Estimated at 10-year time lag.

IHD, ischaemic heart disease.

availability of energy from fruit, meat and vegetable oils was also associated with lower rates of stunting although to a smaller extent, while a greater proportion of energy available from cereals, animal fats and pulses was associated with higher rates of stunting.

Increased availability of energy from four of the nine non-cereal food groups was associated with significantly lower mortality rates from IHD (table 5). Higher proportional availability of energy from vegetables, pulses and fruit was associated with 459, 278 and 182 fewer IHD deaths per $100000 / 100 \mathrm{kcal}$ increased availability respectively, while higher proportional availability of energy from meat, milk products, sugar and starchy roots available in the diet was associated with greater IHD mortality.

\section{Development measures and nutrition and health outcomes}

Finally, we explored the relationships between measures of development, stunting in childhood and IHD mortality in adults (table 5). In fully adjusted models, increases in GNI were significantly associated with both reduced stunting (1985-2009) and reduced mortality from IHD (1990-2009). Increased urbanisation was associated with decreased rates of stunting and increased rates of mortality from IHD, and employment in agriculture was associated with increased stunting but reduced IHD mortality. The rate of policy assistance for agriculture was not significantly related to either outcome.

\section{DISCUSSION \\ Principal findings}

To our knowledge, this is the first study to combine global data on the availability of different food groups, diverse measures of development, and health and nutrition outcomes in a single analysis for the purpose of exploring relationships between dietary quality, nutrition and health over time. We found that overall dietary energy availability was inversely associated with stunting in children and showed a non-significant trend of a positive association with mortality from IHD in adults. These relationships varied according to World Bank Region, with relationships with child stunting appearing stronger in Asian countries and weaker in sub-Saharan Africa, Eastern Europe and Latin America. The strength of the relationship with IHD mortality appeared to be related to the level of development of the region, with more developed regions showing a far stronger relationship between energy availability and mortality.

Table 3 Mixed effects regression model showing relationships between total energy availability and health outcomes by region

\begin{tabular}{|c|c|c|}
\hline \multirow[t]{2}{*}{$\begin{array}{l}\text { Impact of } 100 \mathrm{kcal} \text { increase in total } \\
\text { energy/capita/day }\end{array}$} & \multicolumn{2}{|c|}{ Change in health outcome (95\% Cls) } \\
\hline & Child stuntingt & $\begin{array}{l}\text { Mortality from IHD } \\
\text { per } 100000 \dagger \ddagger\end{array}$ \\
\hline Eastern Europe/Central Asia $(n=200 / 500)$ & $-0.07(-0.13 \text { to }-0.02)^{\star *}$ & $5.88(-0.47$ to 12.2$)$ \\
\hline Middle East and North Africa $(n=200 / 40)$ & $-0.80(-1.06 \text { to }-0.53)^{\star \star \star}$ & $23.9(-8.03$ to 55.9$)$ \\
\hline Sub-Saharan Africa $(n=725 / 40)$ & $-0.44(-0.56 \text { to }-0.32)^{\star \star \star}$ & $-26.1(-172$ to 120$)$ \\
\hline Latin America/Caribbean $(n=575 / 440)$ & $-0.34(-0.47 \text { to }-0.21)^{\star \star \star}$ & $9.81(5.79 \text { to } 13.8)^{\star \star \star}$ \\
\hline East Asia/Pacific $(n=125 / 140)$ & $-1.13(-1.68 \text { to }-0.57)^{\star \star \star}$ & $7.06(-8.75$ to 22.9$)$ \\
\hline Western Europe $(n=0 / 360)$ & $N / A$ & $18.9(10.2 \text { to } 27.6)^{\star * \star}$ \\
\hline South Asia $(n=125 / 0)$ & $-1.20(-2.51$ to 0.10$)$ & $\mathrm{N} / \mathrm{A}$ \\
\hline US/Canada $(n=0 / 40)$ & $N / A$ & $15.5(4.00 \text { to } 27.0)^{\star *}$ \\
\hline
\end{tabular}

${ }^{*} p$ value for coefficient $<0.05$; ${ }^{* *} p$ value for coefficient $<0.01$; ${ }^{* *} p$ value for coefficient $<0.001$.

†Adjusted for year of measurement, gross national income, percentage employment in agriculture and percentage living in urban areas. † Estimated at 10-year time lag.

IHD, ischaemic heart disease; N/A, not applicable. 
Table 4 Contribution of each food group to total global energy availability (1980-2009)

\begin{tabular}{lcccr}
\hline Food group & $\begin{array}{l}\text { Mean } \\
\text { overall energy } \\
\text { (kcal/capita/day) }\end{array}$ & $\begin{array}{l}\text { Mean energy 1980 } \\
\text { (kcal/capita/day) }\end{array}$ & $\begin{array}{l}\text { Mean energy 2009 } \\
\text { (kcal/capita/day) }\end{array}$ & \begin{tabular}{c}
\multicolumn{1}{c}{$\begin{array}{l}\text { Overall share of total } \\
\text { energy availability* }\end{array}$} \\
(\%)
\end{tabular} \\
\hline Animal fats & 94.8 & 112.0 & 81.2 & 3.5 \\
Cereals & 1104.0 & 1108.4 & 1127.4 & 40.3 \\
Fruit & 100.7 & 98.8 & 108.5 & 3.7 \\
Meat & 204.9 & 196.3 & 217.0 & 7.5 \\
Milk products & 173.4 & 172.2 & 183.3 & 6.3 \\
Pulses & 57.1 & 61.3 & 59.1 & 2.1 \\
Starchy roots & 175.5 & 178.2 & 174.4 & 6.4 \\
Sugar/sweeteners & 294.7 & 311.3 & 290.4 & 10.8 \\
Vegetable oils & 255.0 & 210.5 & 296.7 & 1.9 \\
Vegetables & 52.5 & 45.4 & 63.9 & 9.3 \\
\hline *Mean total energy availability $1980-2009=2740.7$ kcals/capita/day. & &
\end{tabular}

For the first time we also demonstrated that the proportion of total dietary energy available from different food groups, as a proxy for dietary quality, was in many cases more strongly associated with nutrition and health outcomes than overall energy availability. However, this was highly dependent on the non-staple food groups in question. For instance, across all countries on average a $100 \mathrm{kcal}$ increase in total dietary energy availability over the period $1985-2009$ was associated with a $0.84 \%$ reduction in stunting in childhood, while the same increase in proportional energy availability specifically from vegetables was associated with a $3 \%$ reduction in child stunting. Similarly, we found that a $100 \mathrm{kcal}$ increase in total dietary energy availability was associated with an increase in IHD mortality in adults of 4 deaths per 100000 over the period 1990-2009 (non-significant), while the same increase in proportional energy availability from vegetables was associated with a reduction in IHD mortality of 459 deaths per 100000 population. The analysis also suggested that while improved dietary quality in general was associated with reduced stunting rates in children, it was not unequivocally beneficial for IHD, where increased availability of several food groups was associated with higher IHD mortality rates.
Our analysis also investigated the relationships between various correlates of development and nutrition and health outcomes. National income was reliably associated with an improvement in both stunting rates and IHD mortality, suggesting that increased national wealth improves health outcomes of nations when considered independently of energy availability. Increased urbanisation was associated with a reduction in stunting and an increase in IHD mortality, suggesting that urbanisation, which is frequently associated with access to more diverse food markets and diversified income sources, may play a part in reducing stunting. However, the increased access in urban areas to food (and especially highly processed foods) appears simultaneously linked to a rise in risks of NCDs. ${ }^{23}$ Employment in agriculture, conversely, was associated with both increased stunting and reduced mortality from IHD suggesting that this form of employment is still a risk factor for childhood growth performance while potentially being protective against the risks of NCDs. Finally, we found no evidence from this analysis that policies designed to support agriculture (as measured by the RRA) have a beneficial relationship with nutrition and health outcomes. Individual country analyses have shown some support for this
Figure 3 Mean availability of energy from nine non-staple food groups, 1980-2009.
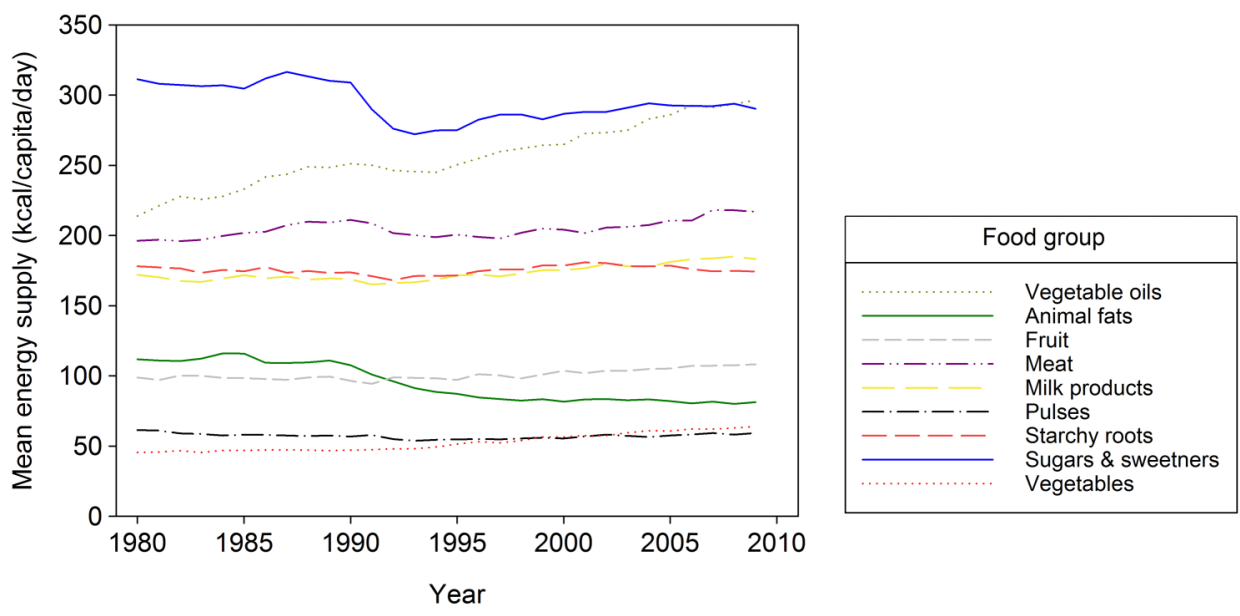
Table 5 Mixed effects models showing relationships between availability of food groups, measures of development and health outcomest

\section{Change in health outcome}

Child stunting \%

IHD mortality rate in over 55 s per 100000 populationๆ

Food availability per capita per day (100 kcal increase)
Cereals
Meat
Milk products
Animal fats
Vegetable oils
Fruits
Vegetables
Starchy roots
Pulses
Sugar and sweeteners
Development indicators
Gross national income $(\$ 1000$ increase)
$\%$ employed in agriculture $(10 \%$ increase)
$\%$ living in urban areas $(10 \%$ increase $)$
Assistance for agriculture $(+$ vs -$) \S$

$0.55(0.42 \text { to } 0.68)^{\star \star \star}$
$-0.65(-1.15 \text { to }-0.15)^{\star \star}$
$-2.13(-2.84 \text { to }-1.41)^{\star \star \star}$
$3.96(2.68 \text { to } 5.24)^{\star \star}$
$-0.62(-1.01 \text { to }-0.23)^{\star *}$
$-0.52(-0.94 \text { to }-0.08)^{\star}$
$-3.45(-5.08 \text { to }-1.81)^{\star \star \star}$
$0.04(-0.16$ to 0.24$)$
$2.31(1.66 \text { to } 2.96)^{\star \star \star}$
$-1.79(-2.24 \text { to } 1.34)^{\star \star \star}$
$-0.57(-0.72 \text { to }-0.43)^{\star \star *}$
$1.36(1.09 \text { to } 1.62)^{\star \star \star}$
$-1.48(-1.09 \text { to }-1.22)^{\star \star *}$
$0.31(-2.48$ to 3.10$)$

$-28.4(-37.5 \text { to }-19.3)^{\star \star \star}$ $50.3(29.7 \text { to } 70.9)^{\star \star \star}$ $148(121 \text { to } 174)^{\star \star \star}$ $1.84(-21.7$ to 25.4$)$

$-78.5(-96.8 \text { to }-60.2)^{\star \star *}$

$-182(-221 \text { to }-142)^{\star \star *}$

$-459(-537 \text { to }-381)^{\star \star \star}$

$100(73.7 \text { to } 127)^{\star * *}$

$-278(-344 \text { to }-212)^{\star \star *}$

$174(154 \text { to } 195)^{\star \star \star}$

$-10.1(-14.6 \text { to }-5.52)^{\star \star \star}$

$-2.86(-20.2$ to 14.5$)$

$37.2(23.9 \text { to } 50.5)^{\star * *}$

$8.17(-27.4$ to 43.8$)$

${ }^{*} p$ value $<0.05 ;{ }^{* *}$ p value $<0.01 ;{ }^{* * *} p$ value $<0.001$

†Model includes World Bank Region as an area-level effect.

$\ddagger$ Adjusted for total energy availability, year of measurement, gross national income, \% employed in agriculture and \% living in urban areas.

$\S$ Subgroup analysis on 1021 observations only.

IEstimated at 10 -year time lag.

IHD, ischaemic heart disease.

phenomenon, such as work on the agriculture-nutrition disconnect in India. ${ }^{24}$

\section{Limitations}

There are a number of limitations to this analysis, chief among these being that our study is ecological and therefore cannot ascribe causality to the relationships observed. The global and wide-ranging nature of the study also means that necessarily some precision in the data will have been lost due to measurement error and missing data. Most of these issues will have been likely to lead to underestimation of the relationships we examined. For example, the countries where few or inaccurate data are available may be the very countries where problems of food availability and child undernutrition are greatest, which may have led us to underestimate our relationships with child stunting. Correction factors for some global data have recently become available, which may assist with future analyses. ${ }^{25}$ Also, IHD mortality is a hard disease end point and therefore could not be expected to show a concurrent relationship with food availability; we dealt with this problem by adding a 10-year time lag to our mortality analyses, but this reduced the sample size for these analyses as we were consequently only able to consider mortality from 1990 onwards in our final models. Finally, missing data were dealt with through multiple imputation where this was possible, but a number of countries had to be excluded from the analysis entirely. As a result, the sample of countries with data on child stunting has a different income profile from those countries with data on IHD mortality (because child stunting data are not recorded for high-income countries and many low income countries had missing data on mortality) and therefore we were unable to compare rates of undernutrition and NCDs over time within the same country. This may also affect the generalisability of our results to countries that have poor data availability on either or both of these measures, and means that we were unable to examine the complex interactions between undernutrition and NCDs that may be at play in some of these countries.

\section{Comparison with previous studies}

A few previous studies have investigated the association of national-level dietary patterns and specific dietary components with nutrition and health outcomes. Single-country studies have shown that increased dietary diversity is associated with reductions in childhood stunting prevalence in Bangladesh, ${ }^{26}$ Cambodia $^{27}$ and China, ${ }^{28}$ and that diets high in protein are associated with reduced stunting in Iran. ${ }^{29}$ Ours is the first study to explore the importance of dietary quality on stunting in childhood across multiple countries over time. Per capita availability of dietary fat and oil crops have shown positive associations with the prevalence of obesity and CVD mortality at the population level in previous crosssectional multicountry studies. ${ }^{11} 13{ }^{30}$ Our analysis did not find evidence of a similar association when fats and oils were considered as a proportion of total energy availability, instead we found that availability of meat 
and dairy products as a proportion of the diet were independently and more strongly associated with IHD mortality in adults. Our results demonstrate that food group diversity per se is not wholly positive for nutrition and health outcomes, and that complex relationships with animal source foods, fruit and vegetables would have been masked had we used a single measure of diversity as most previous studies have done. Finally, our study also expands on previous work in the area of global food availability by including adjustment for measures of development, providing a contemporaneous comparison between a critical measure of child undernutrition and the leading cause of adult diet-related mortality.

\section{Conclusions and policy implications}

This study provides new evidence to help support agricultural, nutrition and health policymakers to understand the important relationships between diet, nutritional status and NCDs. Our analysis identifies a key question, namely how can policymakers tackle child undernutrition without increasing the risk of NCDs in future generations? Dietary diversity as well as adequate energy supply is clearly important for health outcomes, particularly child stunting. In particular, increased availability of energy from fruit and vegetables appears to be associated with both a reduction in stunting in childhood and in IHD mortality in adults. Increasing the supply and accessibility of these foods is therefore likely to be unequivocally beneficial for population-wide health and our analysis suggests that this should be a major focus for agricultural policy that has a real potential to enhance health outcomes.

However, for other food groups the picture is more mixed and likely to be dependent on the level of development of the country in question, as shown by our regional analyses. An increase in the supply of meat and dairy products was strongly related to reduced child stunting, but these foods also appeared to be related to increased mortality from IHD. ${ }^{31}$ Similarly, an increased supply of sugar, while a source of additional energy to reduce stunting, also appears to be associated with increased IHD mortality. Policy-level support for increased production of animal source and high-sugar foods therefore requires careful consideration of the trade-offs between different health outcomes and policy options will differ by country context. This may be particularly important for countries currently facing a double burden of remaining child undernutrition along with increasing mortality from NCDs.

An optimal diet in terms of quality is clearly essential to both of the outcomes we studied here, but our results indicate that this optimum may be different depending on the nutrition or health outcome in question. Therefore, the search for food policies to support healthy diets needs to be framed by a much more nuanced understanding of how foods combine together to form a complete diet in order for useful interventions to be designed. Finally, in defining high quality diets it is important also to consider the needs of other sectors such as the environment-sustainable as well as healthy diets will be vital in designing future policy, and balancing health with sustainability is not always straightforward. Our study has demonstrated that by combining large, publicly available data sets, important patterns underlying trends in diet-related health can be uncovered. Further work and joined-up multisectoral thinking will be required to translate these patterns into policies that can improve nutrition and health outcomes globally.

\section{Author affiliations}

${ }^{1}$ Department of Population Health, London School of Hygiene \& Tropical Medicine, London, UK

${ }^{2}$ Leverhulme Centre for Integrative Research on Agriculture and Health (LCIRAH), London, UK

${ }^{3}$ Centre for Development, Environment and Policy, School of Oriental and African Studies, London, UK

${ }^{4}$ Friedman School of Nutrition Science and Policy, Tufts University, Boston, Massachusetts, USA

Acknowledgements The authors would like to thank Majid Ezzati and Prakash Shetty for their valuable contributions to this paper. Special thanks must also go to Josef Schmidhuber for supplying a complete download of the FAOSTAT Food Balance Sheet database.

Contributors RG, ADD and PW designed the study; RG and JS obtained and analysed the data; RG, JS, $A D D, B S$ and PW interpreted the data; RG initially drafted the paper and JS, ADD, BS and PW revised it; and RG, JS, ADD, BS and PW gave final approval of the version to be published. All authors give their agreement to be accountable for all aspects of the work in ensuring that questions related to the accuracy or integrity of any part of the work are appropriately investigated and resolved. All authors also had full access to all of the data and can take responsibility for the integrity of the data and the accuracy of the data analysis. RG acts as guarantor for the paper.

Funding Support for this study was provided by the Feed the Future Innovation Lab for Nutrition, which is funded by the USA Agency for International Development. Cooperative Agreement with Tufts University No. AID-OAA-L-10-00006.

Competing interests None declared.

Provenance and peer review Not commissioned; externally peer reviewed.

Data sharing statement Data set is available by emailing the corresponding author.

Open Access This is an Open Access article distributed in accordance with the Creative Commons Attribution Non Commercial (CC BY-NC 4.0) license, which permits others to distribute, remix, adapt, build upon this work noncommercially, and license their derivative works on different terms, provided the original work is properly cited and the use is non-commercial. See: http:// creativecommons.org/licenses/by-nc/4.0/

\section{REFERENCES}

1. Mazzocchi M, Shankar B, Traill B. The development of global diets since ICN 1992: Influences on agri-food sector trends and policies. FAO Commodity and Trade Policy Research Working Paper no.34. Rome: FAO, 2012.

2. Smith LC, Haddad LJ. Reducing child undernutrition: past drivers and priorities for the post-MDG era. IDS Working Paper 2014:2014:1-47.

3. UNICEF Levels and Trends in Child Malnutrition. (UNICEF-WHOWorld Bank Group joint child malnutrition estimates). 2015.

4. Haddad LJ, Hawkes C, Udomkesmalee E, et al. Global Nutrition Report 2014: Actions and accountability to advance nutrition and sustainable development. Washington DC, USA: International Food Policy Research Institute, 2014. 
5. Smith LC, Haddad LJ. How important is improving food availability for reducing child malnutrition in developing countries? Agr Econ 2001;26:191-204.

6. Headey DD. Developmental drivers of nutritional change: a cross-country analysis. World Dev 2013;42:76-88.

7. Mazzocchi M, Traill B. Calories, obesity and health in OECD countries. Appl Econ 2011;43:3919-29.

8. Remans R, Wood SA, Saha N, et al. Measuring nutritional diversity of national food supplies. Global Food Security 2014;3:174-82.

9. Imamura F, Micha R, Khatibzadeh S, et al., Global Burden of Diseases Nutrition and Chronic Diseases Expert Group (NutriCoDE) Dietary quality among men and women in 187 countries in 1990 and 2010: a systematic assessment. Lancet Glob Health 2015;3: e132-42.

10. Zatonski WA, McMichael AJ, Powles JW. Ecological study of reasons for sharp decline in mortality from ischaemic heart disease in Poland since 1991. BMJ 1998;316:1047-51.

11. Moussavi N, Gavino V, Receveur O, Is obesity related to the type of dietary fatty acids? An ecological study. Public Health Nutr 2008;11:1149-55.

12. Siegel KR, Echouffo-Tcheugui JB, Ali MK, et al. Societal correlates of diabetes prevalence: an analysis across 94 countries. Diabetes Res Clin Pract 2012;96:76-83.

13. MacDonald J, Brevard PB, Lee RE, et al. Link between diet and cardiovascular disease in Latin America and the Caribbean using geographic information systems. Rev Panam Salud Pública 2009;26:290-8.

14. Chen BK, Seligman B, Farquhar JW, et al. Multi-Country analysis of palm oil consumption and cardiovascular disease mortality for countries at different stages of economic development: 1980-1997. Global Health 2011;7:45.

15. Basu S, Yoffe P, Hills N, et al. The Relationship of sugar to population-level diabetes prevalence: an econometric analysis of repeated cross-sectional data. PLoS ONE 2013;8:e57873.

16. Black RE, Victora CG, Walker SP, et al. Maternal and child undernutrition and overweight in low-income and middle-income countries. Lancet 2013;382:427-51.

17. Lim SS, Vos T, Flaxman AD, et al. A comparative risk assessment of burden of disease and injury attributable to 67 risk factors and risk factor clusters in 21 regions, 1990-2010: a systematic analysis for the Global Burden of Disease Study 2010. Lancet 2012:380:2224-60.

18. Stevens GA, Finucane MM, Paciorek CJ, et al. Nutrition Impact Model Study Group (Child Growth). Trends in mild, moderate, and severe stunting and underweight, and progress towards MDG 1 in 141 developing countries: a systematic analysis of population representative data. Lancet 2012;380:824-34

19. Food and Agriculture Organization. FAOSTAT food supply data http://faostat3.fao.org/home/E (accessed Jun 2015).

20. The World Bank. World Development Indicators http://data. worldbank.org/data-catalog/world-development-indicators (accessed Jun 2015).

21. Anderson K, Valenzuela E. Updated national and global estimates of distortions to agricultural incentives, 1955 to 2011. Washington DC, USA: The World Bank, 2013.

22. von Braun J, Serova E, Tho SH, et al. Russia's food economy in transition: what do reforms mean for the long-term outlook? 2020 Vision Brief 36: A 2020 Vision for Food, Agriculture, and the Environment, Washington DC, USA: International Food Policy Research Institute, 1996

23. Webb $\mathrm{P}$, Block $\mathrm{S}$. Support for agriculture during economic transformation: impacts on poverty and undernutrition. Proc Natl Acad Sci USA 2012;109:12309-14.

24. Gillespie S, Harris J, Kadiyala S. The agriculture-nutrition disconnect in India: what do we know? IFPRI Discussion Paper 01187. International Food Policy Research Institute, 2012

25. Del Gobbo LC, Khatibzadeh S, Imamura F, et al. Assessing global dietary habits: a comparison of national estimates from the FAO and the Global Dietary Database. Am J Clin Nutr 2015;101:1038-46.

26. Rah JH, Akhter N, Semba RD, et al. Low dietary diversity is a predictor of child stunting in rural Bangladesh. Eur J Clin Nutr 2010;64:1393-8.

27. Darapheak C, Takano T, Kizuki M, et al. Consumption of animal source foods and dietary diversity reduce stunting in children in Cambodia. Int Arch Med 2013;6:29.

28. Li YP, Wedick NM, Lai J, et al. Lack of dietary diversity and dyslipidaemia among stunted overweight children: the 2002 China National Nutrition and Health Survey. Public Health Nutr 2011;14:896-903.

29. Esfarjani F, Roustaee R, Mohammadi-Nasrabadi F, et al. Major dietary patterns in relation to stunting among children in Tehran, Iran. J Health Popul Nutr 2013;31:202-10.

30. Artaud-Wild SM, Connor SL, Sexton G, et al. Differences in coronary mortality can be explained by differences in cholesterol and saturated fat intakes in 40 countries but not in France and Finland. A paradox. Circulation 1993;88:2771-9.

31. Webb P. Importance of protein quality in prevention and treatment of child malnutrition. Food Nutr Bull 2013;34:226-7. 